\title{
Binding of Cd(II) by Amorphous Aluminum Hydroxide- Organophosphorus Coprecipitates: From Macroscopic to Microscopic Investigation
}

\author{
Lei Lu $\mathbb{D}^{D}$, Feng Xu $(\mathbb{D}$, Wenkai Rao $\mathbb{D}$, Ning Nie $\mathbb{D}$, and Huihui Du \\ Hunan Engineering \& Technology Research Center for Irrigation Water Purification, College of Resources and Environment, \\ Hunan Agricultural University, Changsha 410128, China
}

Correspondence should be addressed to Huihui Du; duhuihui@hunau.edu.cn

Received 8 March 2021; Revised 29 March 2021; Accepted 20 April 2021; Published 28 April 2021

Academic Editor: S Rangabhashiyam

Copyright ( 2021 Lei Lu et al. This is an open access article distributed under the Creative Commons Attribution License, which permits unrestricted use, distribution, and reproduction in any medium, provided the original work is properly cited.

\begin{abstract}
The mobility of $\mathrm{Cd}(\mathrm{II})$ in soils, sediments, and aquatic systems is strongly dependent on adsorption behaviors occurring at the mineral-water interface, and this process may be influenced by the presence of organic phosphorus (OP). In this study, we investigate $\mathrm{Cd}(\mathrm{II})$ adsorption onto amorphous aluminum hydroxide (AAH), both in the presence and absence of OP, represented by the widely abundant myo-inositol hexakisphosphate (IHP). Isothermal adsorption experiment coupled with attenuated total reflection Fourier transform infrared (ATR-FTIR) and ${ }^{1} \mathrm{H}$ solid-state NMR spectra were employed. Physiochemical characterization shows that IHP can increase the surface negative charge and the number of surface sites. Isothermal results show that high IHP loading enhances Cd(II) adsorption while no obvious increase is observed at low IHP loading. The overall effect of IHP on Cd(II) sorption depends on the extent of two positive processes, i.e., (1) IHP can form ternary complexes with adsorbed $\mathrm{Cd}(\mathrm{II})$ on AAH and (2) IHP can increase the negative surface charge of AAH, and a negative process, i.e., AAH competes with $\mathrm{Cd}(\mathrm{II})$ for $\mathrm{AAH}$ surface sites. ATR-FTIR results confirm the possible formation of three structurally distinct ternary complexes, i.e., the AAH-IHP-Cd, AAH-Cd-IHP, and AAH-Cd-IHP-Cd. The analysis of ${ }^{1} \mathrm{H}$ solidstate NMR demonstrates that IHP only increases the number of surface $\mathrm{OH}$ groups rather than changes their chemical environment and speciation. Cd does not bind to the AAH surface but mainly binds with the OH groups of IHP. All findings of this work suggest that the presence of high dose of OP promotes the retention of Cd(II) in soils, thereby decreasing their bioavailability to biota.
\end{abstract}

\section{Introduction}

Heavy metals released from industrial and agricultural activities accumulate in soil, resulting in the degradation of soil quality $[1,2]$. Sorption, desorption, and precipitation reactions of heavy metals onto soil components, i.e., metal (hydr)oxides and organic constituents, determine their mobility, migration, and bioavailability, which remarkably affects crop safety [3-6]. Both iron and aluminum (hydr)oxides are widely present in soils and sediments, especially in tropical and subtropical soils with variable charges [7]. Poorly crystalline Fe/Al (hydr)oxides provide abundant active sorption sites for toxic heavy metals through precipitation $[8,9]$ and complexation [10]. As such, they can be a sub- stantial sink for heavy metal pollutants, thereby governing their biogeochemical cycles in contaminated environment.

In soils, the presence of anionic compounds can enhance or suppress the surface interaction of heavy metals on $\mathrm{Fe} / \mathrm{Al}$ (hydr)oxides [11, 12]. Phosphate is an ubiquitous reactive ligand in the environment, showing high reactivity to soil minerals $[13,14]$. A large number of studies have shown that phosphate can significantly affect heavy metals adsorption onto mineral phases [15-17]. This can occur as the result of the following: (a) electrostatic interaction [18], (b) ternary surface complexion [19], (c) competition with heavy metals for surface adsorption sites [11,20], and (d) formation of metal-phosphate surface precipitation [21]. Ren et al. [22] showed an enhanced adsorption of $\mathrm{Cu}$ (II) with coexisting 
phosphate on $\gamma-\mathrm{Al}_{2} \mathrm{O}_{3}$ at $\mathrm{pH} 5.5$, which is attributed to the formation of ternary surface complexes (phosphate as bridging molecule). Recent research by Hinkle et al. [19] suggested that the synergistic adsorption behavior of phosphate and $\mathrm{Fe}(\mathrm{II})$ is probably due to electrostatic interactions and the ternary complexation formation on Fe oxide surfaces. An earlier study by Li et al. [20] found that phosphate treatment suppresses the maximum adsorption of $\mathrm{Cd} / \mathrm{Cu}$ on hematite, owing to the decreased inner-sphere adsorption sites with coexisting phosphate. Singh et al. [21] also observed the formation of surface ternary complexes of goethite-phosphate$\mathrm{U}$, and $\mathrm{U}(\mathrm{VI})$-phosphate precipitation occurred when $\mathrm{U}(\mathrm{VI})$ concentration was up to $\sim 100 \mu \mathrm{M}$. As mentioned above, most studies have focused on the influences of inorganic phosphate on toxic metals binding to $\mathrm{Fe} / \mathrm{Al}$ (hydr)oxide, but relatively few studies have explored the effects of organic phosphorus.

Organic phosphorus (OP) accounts for 50 80\% of total P in soils, among which myo-inositol hexakisphosphate (IHP) is the most abundant one that is involved in many biogeochemical processes $[23,24]$. It is well documented that IHP can strongly interact with metal (hydr)oxides, such as $\mathrm{Al}$ (hydr)oxide [25-27], Fe (hydr)oxide [28, 29], and metal nanoparticles [30, 31]. The coexisting IHP can significantly promote $\mathrm{Cd}(\mathrm{II})$ sorption on gibbsite and kaolinite below pH 8 [32, 33]. ATR-FTIR spectroscopy results have confirmed two structurally distinct ternary surface complexes in ternary system of IHP, Cd(II), and hematite [23]. Yan et al. [34] investigated the adsorption of $\mathrm{Zn}(\mathrm{II})$ and IHP on $\gamma-\mathrm{Al}_{2} \mathrm{O}_{3}$ surfaces and showed that the presorption of IHP restrains the formation of $\mathrm{Zn}-\mathrm{Al}$ layered double hydroxide $(\mathrm{LDH})$ precipitates. The above results have shown that the presence of IHP can remarkably affect the interaction between heavy metals and minerals. Despite this, very limited studies have investigated the reactivity of minerals-IHP coprecipitates, especially their sorption behavior towards heavy metals.

Amorphous $\mathrm{Al}$ hydroxide (AAH), serving as the most active $\mathrm{Al}$ (hydr)oxides in soils, exhibits a great number of reactive functional groups and high specific surface area $[26,27]$. The adsorption processes of $\mathrm{Cd}(\mathrm{II})$ or IHP on AAH have been systematically studied before $[26,35]$, while the binding mechanisms of $\mathrm{Cd}(\mathrm{II})$ on AAH-IHP coprecipitates are still poorly understood. The spectroscopy technology, i.e., Fourier transform infrared spectroscopy (ATRFTIR) and solid-state ${ }^{1} \mathrm{H}$ nuclear magnetic resonance spectroscopy $\left({ }^{1} \mathrm{H} \mathrm{NMR}\right)$, can provide molecular-scale information for the binding characteristics of heavy metals on mineral surface and allow for the direct identification of their surface species. In the present study, we synthetized AAHIHP coprecipitates with two different $P$ loadings. We characterized the AAH-IHP coprecipitates in terms of mineralogy, crystallinity, surface functional groups, and surface charge. We combined batch sorption, ATR-FTIR spectroscopy, and solid-state ${ }^{1} \mathrm{H}$ NMR spectroscopy to explore the binding mechanisms of $\mathrm{Cd}(\mathrm{II})$ in the composite system. Our finding is helpful to understand the interaction of trace elements with Al-organophosphorus coprecipitates in Al-rich soils and sediments.

\section{Materials and Methods}

2.1. Synthesis of Pure AAH and AAH-IHP Coprecipitates. Myo-inositol hexakisphosphate $\left(\mathrm{C}_{6} \mathrm{H}_{18} \mathrm{O}_{24} \mathrm{P}_{6}\right.$, IHP) was produced from Sigma-Aldrich (Shanghai, China). Amorphous $\mathrm{Al}$ hydroxide (AAH) was prepared according to the method reported previously [26], by adding $0.5 \mathrm{M} \mathrm{NaOH}$ to a $0.167 \mathrm{M} \mathrm{AlCl}_{3}$ solution at $\mathrm{pH} \sim 6.0$. Two kinds of AAH-IHP coprecipitates were synthesized by mixing $0.05 \mathrm{M}$ aluminum nitrate with $1 \mathrm{mM}$ or $10 \mathrm{mM}$ of IHP under vigorous stirring. After $15 \mathrm{~min}$, the $\mathrm{pH}$ of the suspensions was adjusted to 7.3 and then left for 20 min to obtain two different AAH-IHP coprecipitates, named as AAH-IHP_low and AAH-IHP high, respectively. The suspensions were centrifuged at $4500 \times \mathrm{g}$ for $20 \mathrm{~min}$, and the resulting supernatants with unadsorbed IHP were removed. Both the pure AAH and AAH-IHP coprecipitates were washed three times with deionized water and dialyzed for 2 days in the dark. The freshly synthesized AAH and AAH-IHP coprecipitates were employed for batch Cd(II) sorption experiments, and a proportion of the freeze-dried precipitates were used for TEM, XRD, ATR-FTIR, and zeta $(\zeta)$ potential measurements.

2.2. Cd(II) Adsorption Experimental Designs. Cd(II) stock solution was prepared at $1000 \mathrm{mg} / \mathrm{L}$ by dissolving $\mathrm{Cd}\left(\mathrm{NO}_{3}\right)_{2} \cdot 4 \mathrm{H}_{2} \mathrm{O}$ in deionized water. Potassium nitrate $\left(\mathrm{KNO}_{3}\right)$ was prepared at $0.1 \mathrm{M}$ as the background electrolyte. Prior to the sorption experiment, the adsorbents were first dispersed with electrolyte $\left(0.1 \mathrm{M} \mathrm{KNO}_{3}\right)$ and purged with $\mathrm{N}_{2}$ to remove $\mathrm{CO}_{2}$. Sorption experiments were performed in a series of $50 \mathrm{~mL}$ centrifuge tubes at room temperature $\left(\sim 25^{\circ} \mathrm{C}\right)$. In each tube, sorption samples contained $0.1 \mathrm{~g} / \mathrm{L}$ of sorbents (AAH or AAH-IHP coprecipitates), $0 \sim 40 \mathrm{mg} / \mathrm{L}$ $\mathrm{Cd}$, and background electrolyte. The sorption suspensions were immediately shaken for 24 hours at $\mathrm{pH} 6.5$ and then centrifuged at $4500 \times \mathrm{g}$ for 10 minutes. The supernatants were filtered through $0.22 \mu \mathrm{m}$ membrane filters and acidified with $1 \% \mathrm{HNO}_{3}$ for measurement of $\mathrm{Cd}(\mathrm{II})$ using ICP-OES (PerkinElmer Optima 8300). The residual solids were freeze-dried for selected analyses of ATR-FTIR and ${ }^{1} \mathrm{H}$ solid-state NMR. All the measurements were performed in three replicates, and sample blanks were conducted throughout the whole processes. The Langmuir isotherm (Eq. (1)) was used to model the results [36]:

$$
Q_{e}=\frac{Q_{m} K C_{e}}{1+K C_{e}},
$$

where $Q_{e}(\mathrm{mg} / \mathrm{g})$ and $Q_{m}(\mathrm{mg} / \mathrm{g})$ refer to the equilibrium adsorption capacity and maximum adsorption capacity, respectively. $K(\mathrm{~L} / \mathrm{mg})$ represents the Langmuir constant, and $C_{e}(\mathrm{mg} / \mathrm{L})$ is the equilibrium concentration after adsorption.

2.3. Characterization of Pure AAH and AAH-IHP Coprecipitates with or without Adsorbed Cd(II). The morphology of pure AAH and AAH-IHP coprecipitates was recorded using a transmission electron microscopy (TEM, FEI Tecnai G2 F20, US) after fixing them with $2.5 \%$ 
glutaraldehyde. The mineral identity was analyzed on a Bruker D8 Advance diffractometer (XRD, Shimadzu XRD-6100) equipped with a $\mathrm{Cu} K \alpha$ radiation $(\lambda=1.5406 \mathrm{~nm})$. Diffractograms were collected from $1^{\circ}$ to $85^{\circ}$ with a $10 \mathrm{~s}$ acquisition time and a step size of $0.02^{\circ}$. The surface charge property was determined by a zeta potential analyzer (Zetaplus90, Brookhaven). Prior to zeta potential collection, the freshly samples $(0.1 \mathrm{~g} / \mathrm{L})$ were dispersed in $0.1 \mathrm{M} \mathrm{KNO}_{3}$ at $\mathrm{pH} 6.5$. ATR-FTIR was performed on a PerkinElmer FT-IR spectrometer equipped with an advanced 6 reflection ATR units (Specac Ltd. London, U.K.). Each spectrum was recorded in the range extending from $800 \mathrm{~cm}^{-1}$ to $2600 \mathrm{~cm}^{-1}$ at a resolution of $4 \mathrm{~cm}^{-1}$. Solid-state ${ }^{1} \mathrm{H}$ NMR spectra were recorded on a $600 \mathrm{MHz}$ Bruker spectrometer $(11.74 \mathrm{~T})$ equipped with a high-speed MAS probe. ${ }^{1} \mathrm{H}$ MAS-NMR spectra were measured with an excitation $\pi / 2$ pulse of width $6 \mu$ s and a $20 \mathrm{~s}$ relaxation delay. Trimethylsilane solution was employed as the external standard to calibrate the chemical shift. The experimental error was $\pm 0.1 \mathrm{ppm}$ for the shift.

\section{Result}

3.1. Physiochemical Characteristics of AAH-IHP Coprecipitates. The results of TEM and XRD are presented in Figure 1. According to the TEM images, both pure AAH and AAHIHP coprecipitates show networks of coalesced aggregates, which are composed of amorphous and nanosized particles. This finding indicates the formation of poorly crystalline $\mathrm{Al}$ hydroxide [7]. No significant differences are observed between pure AAH and AAH-IHP coprecipitates. The XRD pattern of pure AAH exhibits three broad peaks at $\sim 0.42,0.22$, and $0.14 \mathrm{~nm}$, which agrees with those of amorphous $\mathrm{Al}$ hydroxide [26]. By comparison, AAH-IHP coprecipitates show slightly reduced crystallinity according to the decreased peak intensity at 0.22 and $0.14 \mathrm{~nm}$. The possible explanation is that the frequent reactions between AAH and IHP molecules prevent cross-linking and lead to the reduced size of coherent scattering domains [37]. Combined results of TEM and XRD analyses demonstrate that IHP can slightly alter the surface structure of $\mathrm{AAH}$, which agrees with other organo-AAH composites reported previously $[7,26]$.

ATR-FTIR spectra are regarded as an efficient technique to identify IR vibrations of the OP molecules and to characterize the interaction between OP and minerals by changing these vibrations [23, 34]. The ATR-FTIR spectra $\left(800 \sim 2600 \mathrm{~cm}^{-1}\right)$ of IHP interacted with AAH are given in Figure 1(e). The absorbance band at $\sim 2427 \mathrm{~cm}^{-1}$ is assigned to the Al-OH vibration. The bands at $\sim 1065$ and $1176 \mathrm{~cm}^{-1}$ correspond to the symmetric and asymmetric stretching vibration of $\mathrm{P}-\mathrm{O}$ [25], while the bands at $\sim 932$ and $883 \mathrm{~cm}^{-}$ ${ }^{1}$ are assigned to the $\mathrm{P}-\mathrm{OH}$ vibration. The characteristic peak of C-C in IHP molecule locates at $\sim 1724 \mathrm{~cm}^{-1}$. In general, in the range of $800 \sim 1200 \mathrm{~cm}^{-1}$ and $\sim 1724 \mathrm{~cm}^{-1}$, most characteristic bands for IHP molecules are observed in high IHPreacted samples. With the increase of initial IHP loading, the original absorbance band at $\sim 946 \mathrm{~cm}^{-1}$ gradually disappears, which accords with the results of Yan et al. [26]. The increased IHP loading decreases the absorbance band at $\sim 2427 \mathrm{~cm}^{-1}$, which may result from inner-sphere surface complex formation between AAH and IHP [38]. The intensity of the absorbance bands at $\sim 1065$ and $1176 \mathrm{~cm}^{-1}$ is enhanced as IHP loading increases, and the spectrum of AAH-IHP_high shows the presence of characteristic peaks of C-C $\left(\sim 1724 \mathrm{~cm}^{-1}\right)$ and P-OH $\left(\sim 932\right.$ and $\left.883 \mathrm{~cm}^{-1}\right)$ vibrations of IHP molecule. These results indicate that high OP loading plays a key role in changing the mineral surface property, and thus affecting their environmental reactivity.

Zeta potentials of AAH and AAH-IHP coprecipitates are presented in Table 1. Our results show that the IHP loading decreases the zeta potentials of AAH from 3.85 to $2.56 \mathrm{mV}$, which agrees with other mineral systems reported previously $[23,27,39]$. However, the low IHP loading only reduces the amount of surface positive change. When the IHP concentration further increases, the surface adsorption sites become increasingly negatively charged, which are favorable to attract cations such as $\mathrm{Cd}^{2+}$ onto mineral surfaces.

3.2. Isothermal Adsorption. Cd(II) adsorption isotherms at pH6.5 are displayed in Figure 2. The goodness $(R>0.97$, Table 2) of fits in Table 2 signifies that Langmuir model can adequately simulate $\mathrm{Cd}(\mathrm{II})$ adsorption onto pure $\mathrm{AAH}$ and AAH-IHP coprecipitates. The maximum Cd adsorption capacity for AAH, AAH-IHP_low, and AAH-IHP_high are 106.97, 107.63 , and $204.71 \mathrm{mg} / \mathrm{g}$, respectively. AAH-IHP_ high exhibits the highest adsorption capacity. In addition, the binding affinities ( $K$, Table 2 ) for $\mathrm{Cd}(\mathrm{II})$ adsorption on three samples are close to each other, which signifies that high IHP increases the number of adsorption sites rather than changes the affinity between $\mathrm{Cd}(\mathrm{II})$ and $\mathrm{AAH}$. There is no obvious differences between pure $\mathrm{AAH}$ and AAH-IHP low, which implies that low-dose OP treatment nearly exerts no impact on $\mathrm{Cd}(\mathrm{II})$ immobilization on $\mathrm{Al}$ (hydr)oxides.

3.3. ATR-FTIR Spectroscopy. The ATR-FTIR spectra $\left(800 \sim 2600 \mathrm{~cm}^{-1}\right)$ of AAH and AAH-IHP coprecipitates before and after adsorbing $\mathrm{Cd}(\mathrm{II})$ at $\mathrm{pH} 6.5$ are presented in Figure 3. The characteristic peak of AAH at $\sim 2427 \mathrm{~cm}^{-1}$ (Al-OH vibration) decreases after adsorbing $\mathrm{Cd}(\mathrm{II})$. Exceptionally, the spectra of AAH with adsorbed Cd show no obvious differences compared to the Cd-free spectrum. When AAH is coprecipitated with IHP, the spectrum intensity of $\mathrm{P}-\mathrm{OH}$ vibration at $\sim 883$ and $932 \mathrm{~cm}^{-1}$ is reduced, and a new absorbance band at $1038 \mathrm{~cm}^{-1}$ appears, which is associated with the $\mathrm{P}-\mathrm{O}-\mathrm{Cd}$ symmetric stretching vibration [23]. This finding suggests that the adsorbed $\mathrm{Cd}(\mathrm{II})$ replaces hydrogen of the $\mathrm{OH}$ groups on the surface of pure $\mathrm{AAH}$ and AAH-IHP_high. However, the peak intensity of Al$\mathrm{OH}$ vibration $\left(\sim 2427 \mathrm{~cm}^{-1}\right)$ with or without adsorbed $\mathrm{Cd}(\mathrm{II})$ in AAH-IHP_high shows no apparent differences. This observation suggests that $\mathrm{Cd}(\mathrm{II})$ is mainly binding to the IHP molecules instead of AAH in the composites. Moreover, it is interesting that the characteristic peaks of $\mathrm{P}-\mathrm{O}$ $\left(\sim 1176 \mathrm{~cm}^{-1}\right)$ and $\mathrm{C}-\mathrm{C}\left(\sim 1724 \mathrm{~cm}^{-1}\right)$ vibrations in AAHIHP_high with adsorbed $\mathrm{Cd}(\mathrm{II})$ are enhanced. Possible explanation is because a part of IHP is desorbed from AAH-IHP coprecipitates in background electrolyte, and some of the free $\mathrm{Cd}$ ions occupy the adsorption sites of 


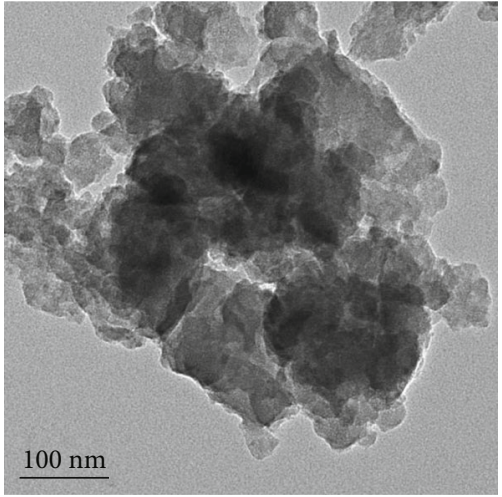

(a)

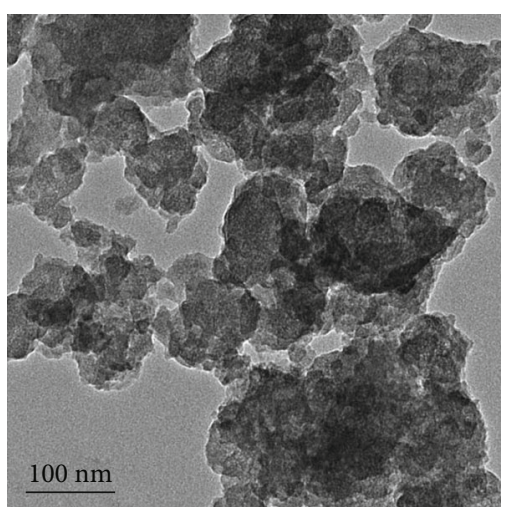

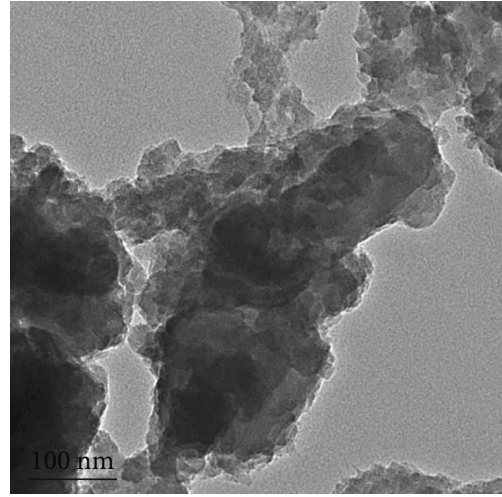

(b)

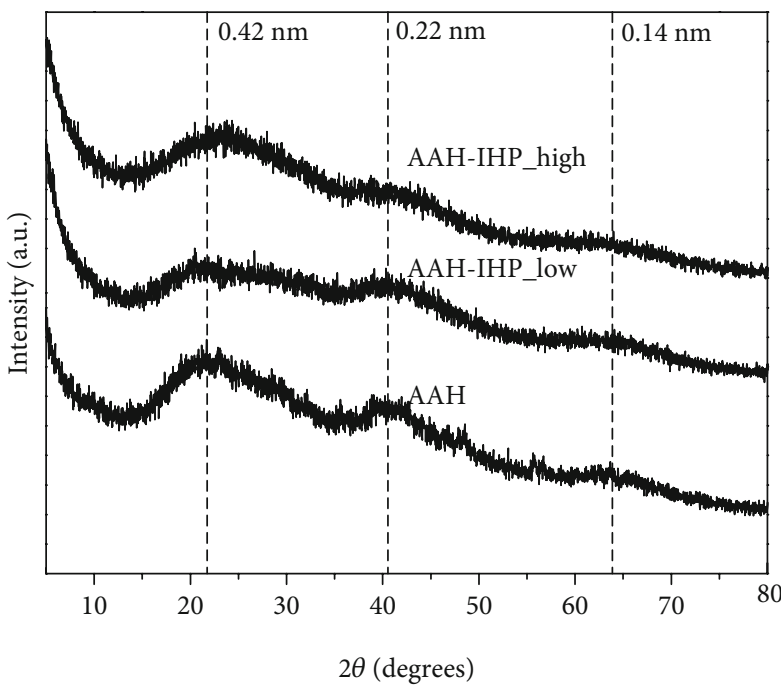

(d)

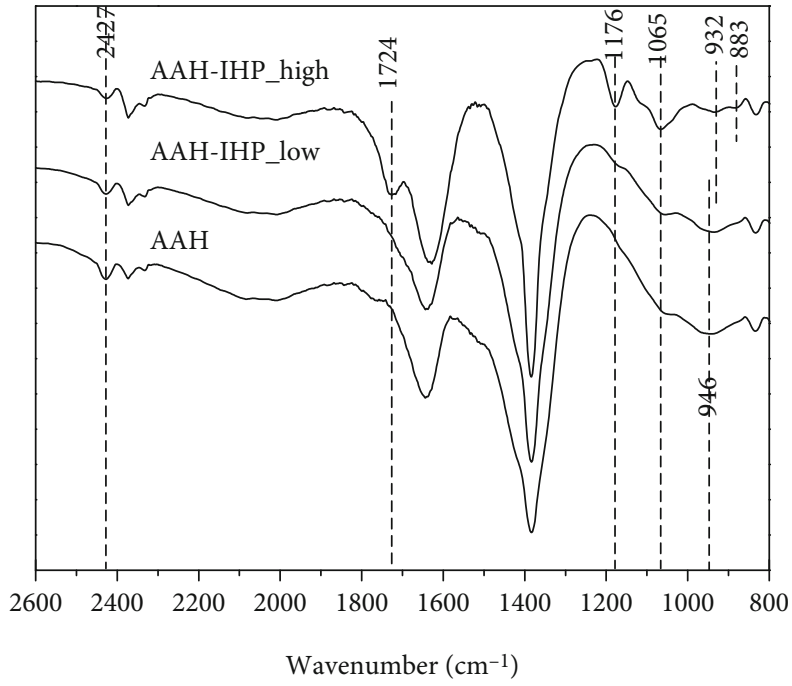

(e)

FIGURE 1: (a-c) TEM, (d) XRD, and (e) ATR-FTIR spectra of pure AAH and AAH-IHP coprecipitates (AAH-IHP_low and AAH-IHP_high).

desorbed IHP on AAH, thus promoting the binding of desorbed IHP with the newly adsorbed Cd on the surface [23, 27].

3.4. ${ }^{1} \mathrm{H}$ Solid-State NMR Spectroscopy. In order to gain a deeper insight into fundamental binding mechanisms of OP interacted with $\mathrm{AAH}$ and their effects on binding of $\mathrm{Cd}$ (II), the ${ }^{1} \mathrm{H}$ NMR spectra of pure AAH and AAH-IHP_high with and without adsorbed $\mathrm{Cd}(\mathrm{II})$ were analyzed and the results are given in Figure 4. The ${ }^{1} \mathrm{H}$ NMR spectra of pure AAH exhibit a main peak at $\delta_{\mathrm{H}-1}=4.7 \mathrm{ppm}$, with two shoulders 
TABLE 1: Zeta potentials of pure AAH and AAH-IHP coprecipitates (AAH-IHP_low and AAH-IHP_high) at pH 6.5.

\begin{tabular}{lc}
\hline Materials & $\mathrm{mV}$ \\
\hline AAH & $3.85(0.08)$ \\
AAH-IHP_low & $1.54(0.06)$ \\
AAH-IHP_high & $-2.56(0.11)$ \\
\hline
\end{tabular}

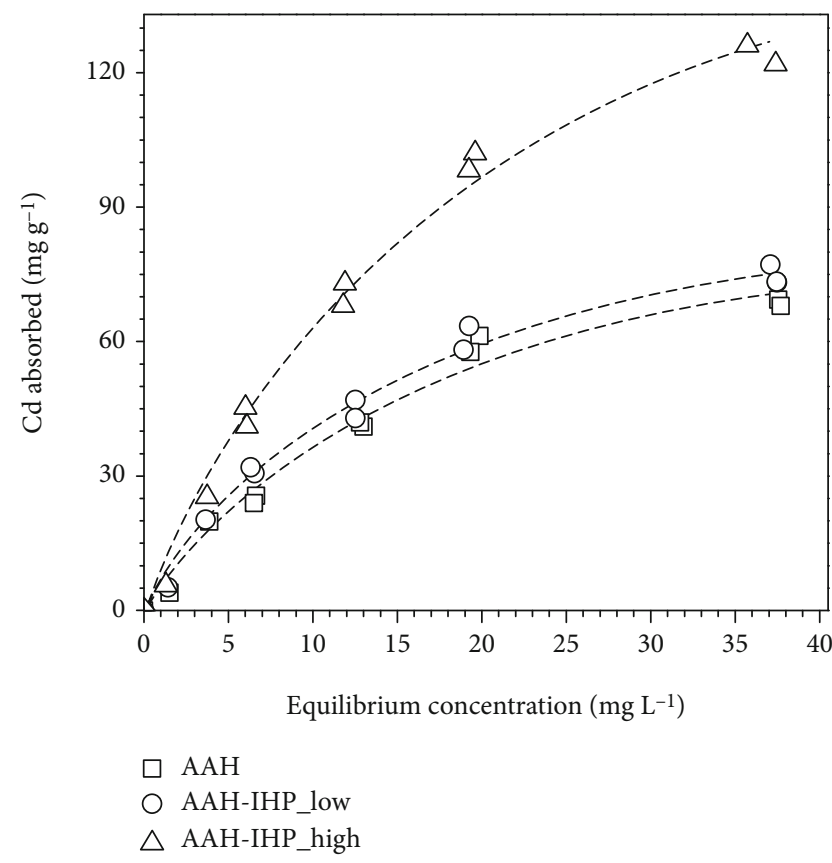

Figure 2: Adsorption isotherms of Cd(II) on pure AAH and AAHIHP coprecipitates (AAH-IHP_low and AAH-IHP_high) at pH 6.5.

TABLE 2: Isotherm parameters for $\mathrm{Cd}(\mathrm{II})$ adsorption on pure $\mathrm{AAH}$ and AAH-IHP coprecipitates (AAH-IHP_low and AAH-IHP_ high) at $\mathrm{pH} 6.5$.

\begin{tabular}{lccc}
\hline Adsorbents & $\begin{array}{l}\text { Langmuir model } \\
Q_{m}(\mathrm{mg} / \mathrm{g})\end{array}$ & $K(\mathrm{~L} / \mathrm{mg})$ & $R^{2}$ \\
\hline AAH & 106.97 & 0.05 & 0.97 \\
AAH-IHP_low & 107.63 & 0.06 & 0.99 \\
AAH-IHP_high & 204.71 & 0.04 & 0.99 \\
\hline
\end{tabular}

Note: $Q_{m}$ is the maximum adsorption capacity, and $K$ represents the Langmuir constant.

around 0.8 and $3.3 \mathrm{ppm}$, respectively. The ${ }^{1} \mathrm{H}$ NMR peak at $4.7 \mathrm{ppm}$ corresponds to the physically adsorbed water, and those at $\delta_{\mathrm{H}-1}=0.8$ and $3.3 \mathrm{ppm}$ are assigned to the $\mathrm{OH}$ groups in AAH or IHP molecule [40]. When IHP is coprecipitated with $\mathrm{AAH}$, the peak intensity at $\delta_{\mathrm{H}-1}=0.8$ and 3.3 increases and no new peak occurs. This result indicates that the chemical environment and speciation of $\mathrm{OH}$ groups in IHP molecule is very similar to that in AAH, and high IHP loading increases the number of $\mathrm{OH}$ groups. On the other hand, the presence of adsorbed $\mathrm{Cd}(\mathrm{II})$ decreases those characteristic peaks of $\mathrm{OH}$ groups at $\delta_{\mathrm{H}-1}=0.8$ and $3.3 \mathrm{ppm}$ in all samples, corresponding to the reduced spectrum intensity at $\sim 883,932$, and $2427 \mathrm{~cm}^{-1}$ observed in Figure 3 . This finding demonstrates that $\mathrm{Cd}(\mathrm{II})$ binds to pure $\mathrm{AAH}$ and $\mathrm{AAH}-$ IHP coprecipitates by surface complexation with $\mathrm{OH}$ groups.

\section{Discussion}

Sorption onto mineral surfaces plays a key role in the mobility, speciation, and bioavailability of heavy metals, thus controlling their eventual fate in soils $[41,42]$. The omnipresence of organic phosphorus (OP) can strongly interact with mineral phases, resulting in a change of the surface charge and reactive surface adsorption sites, and therefore the interaction of mineral surface with many toxic metals $[27,34]$. This research represents a scenario in which Cd(II) occurs in natural environments where $\mathrm{Al}$ (hydr)oxides are associated with OP. The isotherm adsorption results indicate that high IHP loading promotes $\mathrm{Cd}(\mathrm{II})$ adsorption onto $\mathrm{AAH}$ through increasing the adsorption sites, while no obvious increase is observed with low P loading (Figure 2, Table 2). Li et al. [8] demonstrated that $\mathrm{Zn}(\mathrm{II})$ adsorption on $\gamma-\mathrm{Al}_{2} \mathrm{O}_{3}$ in the presence of glyphosate (GPS) is directly bonded with the carboxyl group of GPS and may form $\mathrm{Zn}-\mathrm{Al} \mathrm{LDH}$ precipitates. Li et al. [20] revealed that phosphate decreases the inner-sphere adsorption sites, thus reducing $\mathrm{Cd}(\mathrm{II})$ and $\mathrm{Cu}(\mathrm{II})$ adsorption on hematite. Collins et al. [11] indicated that the enhancement of Cd(II) adsorption onto goethite with coexisting phosphate and sulphate is solely by electrostatic interaction. Therefore, from these results, it could be concluded that the OP in the form of IHP may play several different roles in the ternary systems: (1) IHP molecules are bound to AAH with phosphate groups through the formation of innersphere surface complexes $[25,38]$, which increases the amount of reactive $\mathrm{OH}$ groups (Figure 4), and thus, the adsorption sites are enhanced; (2) at low concentration of IHP loading, the positive charge is reduced (Table 1), but meanwhile, IHP may compete with Cd for the AAH adsorption sites [20,43,44]; (3) when at high IHP loading, the AAH surfaces become more negatively charged, which enhances electrostatic interaction between the minerals and free $\mathrm{Cd}(\mathrm{II})$, and the adsorbed $\mathrm{Cd}(\mathrm{II})$ is mainly bound to the $\mathrm{OH}$ groups in IHP molecule instead of the mineral surface $[8,23]$.

OP not only affects the number of adsorption sites, but also changes the metal species on the mineral surface. Yan et al. [26] revealed that IHP surface complex is formed on $\mathrm{AAH}$ when the reaction time is below $6 \mathrm{~h}$; afterwards, the complexes are rapidly transformed to surface precipitates. Sun et al. [43] showed that less than $12 \%$ of Cd-Al LDH precipitates is emerged when $\mathrm{Cd}(\mathrm{II})$ is interacted with $\gamma-\mathrm{Al}_{2} \mathrm{O}_{3}$ in $18 \mathrm{~h}$ at $25^{\circ} \mathrm{C}$. Recent researches confirmed that the preadsorbed $\mathrm{OP}$ hinders the formation of $\mathrm{Zn}-\mathrm{Al} \mathrm{LDH}$ precipitates on $\gamma-\mathrm{Al}_{2} \mathrm{O}_{3}[8,34]$. Therefore, in our experiment, we speculate that very few $\mathrm{Cd}-\mathrm{Al} \mathrm{LDH}$ precipitates are formed due to the limited reaction time ( $35 \mathrm{~min})$, and ternary surface complex is the main mechanism. To the best of our knowledge, ternary surface complexes can be further classified in general into the following: (1) a type A in which the adsorbed metal ions are near the mineral surface (i.e., $S-M-L$, where $S$, $\mathrm{M}$, and $\mathrm{L}$ represent mineral surface, metal ions, and ligand, 

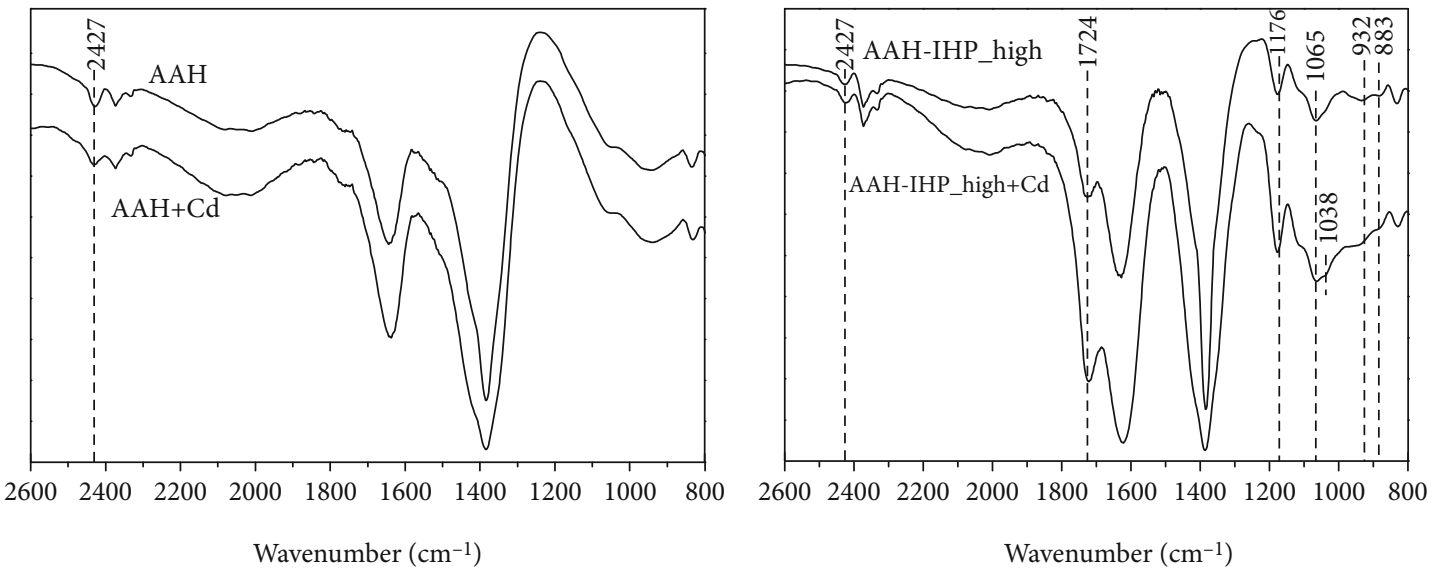

FIgURE 3: ATR-FTIR spectra of pure AAH and AAH-IHP coprecipitates (AAH-IHP_low and AAH-IHP_high) with or without adsorbed Cd.
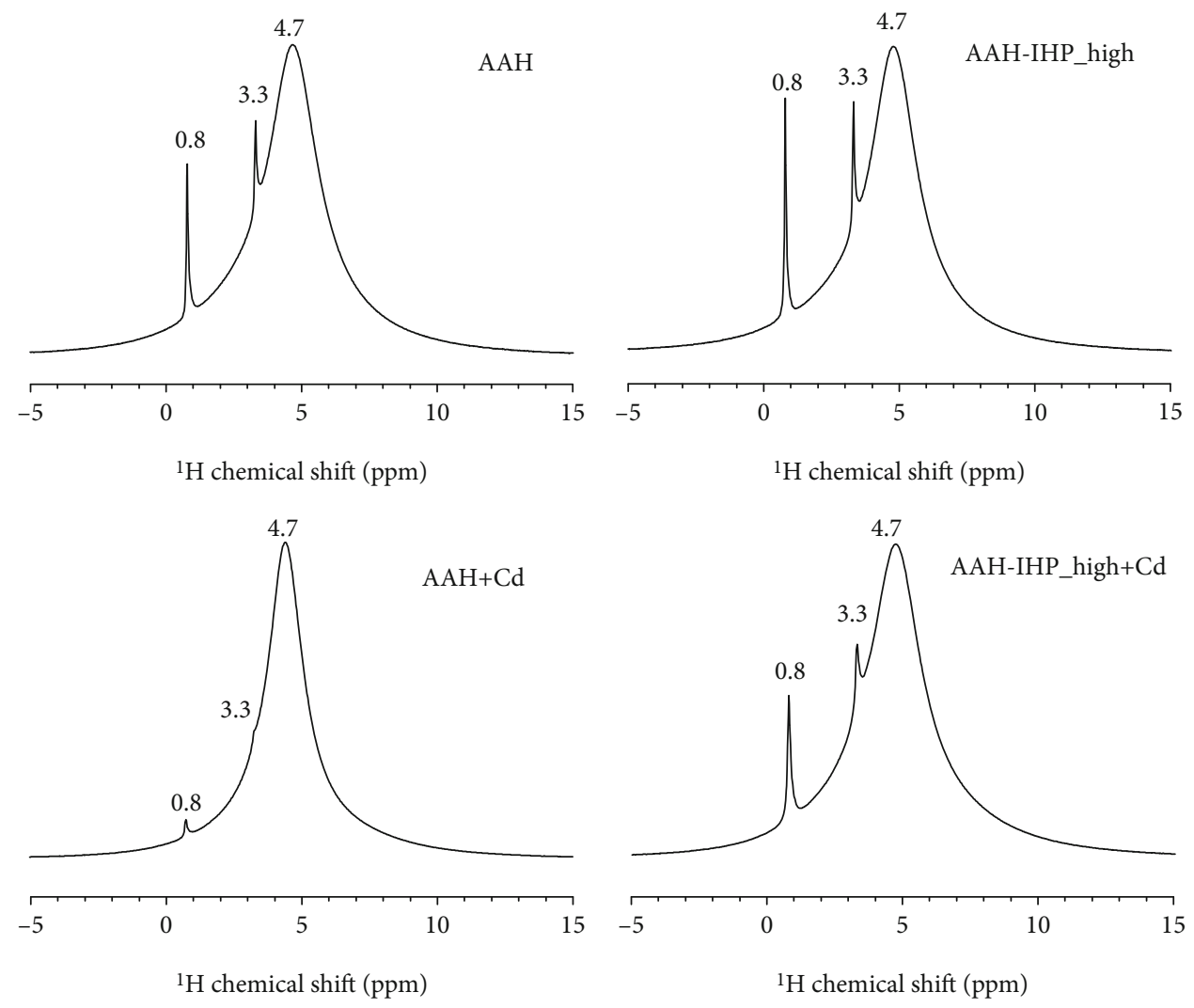

FIgure 4: The ${ }^{1} \mathrm{H}$ NMR spectra of pure AAH and AAH-IHP coprecipitates (AAH-IHP_low and AAH-IHP_high) with or without adsorbed Cd.

respectively) [8]; (2) a type $\mathrm{B}$ in which the adsorbed ligand is near the surface (i.e., S-L-M) [17]; or (3) a type C in which both the metal ion and ligand are near the surface (i.e., S$\mathrm{M}-\mathrm{L}-\mathrm{S})[16,18]$. It is well known that bivalent metal ions can coordinate with two phosphate groups of IHP molecules [45]. Meanwhile, our ATR-FTIR results show that the adsorbed $\mathrm{Cd}(\mathrm{II})$ reduces the characteristic peak of $\mathrm{Al}-\mathrm{OH}$ vibration at $2427 \mathrm{~cm}^{-1}$ while no corresponding reduction is observed in AAH-IHP complexes. These results suggest that the free Cd(II) possibly associates with phosphate groups of
AAH-IHP, which results in the formation of type A ternary surface complexes (AAH-IHP-Cd). In addition, our ATRFTIR results show that the addition of $\mathrm{Cd}$ further promotes the readsorption of desorbed IHP in high IHP treatment, in agreement with the studies reported previously $[23,27]$. This may be attributed to that a small proportion of $\mathrm{Cd}(\mathrm{II})$ is adsorbed by AAH, and the desorbed IHP further binds with the newly adsorbed Cd(II) due to the increased electrostatic attraction. With this in mind, there may appear type $\mathrm{B}$ and $\mathrm{C}$ complexes (AAH-Cd-IHP and AAH-Cd-IHP-Cd) in our 
ternary systems. Due to the formation of the above ternary surface complexes, the coexistence of OP may exert an great impact on the mobility of $\mathrm{Cd}$ (II) in Al minerals and Al-rich soil. Anthropogenic activities lead to the accumulation of both OP and Cd(II) in soil systems [46]. High OP loading enhances the adsorption on $\mathrm{Al}$ (hydr)oxides, therefore decreasing the availability of $\mathrm{Cd}(\mathrm{II})$ to plants. However, low OP loading results in no remarkable promoting effect on adsorption. This provides a new role of $\mathrm{OP}$, that is to say, high OP accumulation in soils would to some extent reduce the environmental risk of $\mathrm{Cd}(\mathrm{II})$ and thus the exposure to biota. On the other hand, our study proposes an ideal for the remediation of heavy metal contaminated soils, that is, to use mineral-organic phosphorus composite to reduce the bioavailability of heavy metals as well as increasing essential phosphorus element for biological growth. Lastly, our study shows progress in the using of ATR-FTIR and NMR to investigate the molecular binding mechanism of heavy metals to mineral-organo composite, and this approach has the potential for wide application in the area of environmental science, where adsorption process is involved.

\section{Conclusions}

The results of this study show that OP facilitates Cd(II) adsorption onto Al hydroxides at high-dose IHP loading (204.71 mg/g), but nearly exhibits no effect at low IHP loading $(107.63 \mathrm{mg} / \mathrm{g})$. ATR-FTIR results show that the adsorbed Cd may have a slight promoting effect on IHP sorption to $\mathrm{AAH}$ in high IHP treatment. IHP interacts intensively with $\mathrm{Al}$ hydroxides by increasing the amount of reactive $\mathrm{OH}$ groups instead of changing the chemical environment and speciation of $\mathrm{OH}$ groups. IHP promotes $\mathrm{Cd}$ adsorption through surface complexation via binding with $\mathrm{OH}$ groups, and several structurally distinct ternary complexes are possibly formed. These findings indicate that coexisting OP at high concentration lowers $\mathrm{Cd}$ mobility in $\mathrm{Al}$ (hydr)oxides or Al-rich soils, and thus the risk to crop safety and human health.

\section{Data Availability}

All data generated or analyzed during this study are included in this published article.

\section{Conflicts of Interest}

The authors declared that there have no potential conflicts of interest that influence the work reported in this paper.

\section{Acknowledgments}

We acknowledge the National Natural Science Foundation of China (41907015) and the Scientific Research Fund of Hunan Provincial Education Department, China (18B120), for financial support.

\section{References}

[1] F. J. Zhao, Y. Ma, Y. G. Zhu, Z. Tang, and S. P. McGrath, "Soil contamination in China: current status and mitigation strategies," Environmental Science \& Technology, vol. 49, no. 2, pp. 750-759, 2015.

[2] B. Huang, Z. Li, J. Huang et al., "Adsorption characteristics of $\mathrm{Cu}$ and $\mathrm{Zn}$ onto various size fractions of aggregates from red paddy soil," Journal of Hazardous Materials, vol. 264, pp. 176-183, 2014.

[3] P. C. Wang, H. Peng, J. L. Liu et al., "Effects of exogenous dissolved organic matter on the adsorption-desorption behaviors and bioavailabilities of $\mathrm{Cd}$ and $\mathrm{Hg}$ in a plant-soil system," Science of the Total Environment, vol. 728, p. 138252, 2020.

[4] M. Siebecker, W. Li, S. Khalid, and D. Sparks, "Real-time QEXAFS spectroscopy measures rapid precipitate formation at the mineral-water interface," Nature Communications, vol. 5, no. 1, p. 5003, 2014.

[5] W. L. Ju, L. Liu, L. C. Fang, Y. Cui, C. Duan, and H. Wu, "Impact of co-inoculation with plant-growth-promoting rhizobacteria and rhizobium on the biochemical responses of alfalfa-soil system in copper contaminated soil," Ecotoxicology and Environmental Safety, vol. 167, pp. 218-226, 2019.

[6] H. Du, C. L. Peacock, W. Chen, and Q. Huang, "Binding of Cd by ferrihydrite organo-mineral composites: implications for Cd mobility and fate in natural and contaminated environments," Chemosphere, vol. 207, pp. 404-412, 2018.

[7] H. du, Q. Y. Huang, M. Zhou et al., "Sorption of $\mathrm{Cu}(\mathrm{II})$ by $\mathrm{Al}$ hydroxide organo-mineral coprecipitates: microcalorimetry and NanoSIMS observations," Chemical Geology, vol. 499, pp. 165-171, 2018.

[8] W. Li, Y. J. Wang, M. Zhu et al., "Inhibition mechanisms of Zn precipitation on aluminum oxide by glyphosate: ${ }^{31} \mathrm{P}$ NMR and Zn EXAFS study," Environmental Science \& Technology, vol. 47, no. 9, pp. 4211-4219, 2013.

[9] Y. Jia, L. Xu, Z. Fang, and G. P. Demopoulos, "Observation of surface precipitation of arsenate on ferrihydrite," Environmental Science \& Technology, vol. 40, no. 10, pp. 3248-3253, 2006.

[10] J. Liu, R. L. Zhu, X. L. Liang et al., "Synergistic adsorption of $\mathrm{Cd}(\mathrm{II})$ with sulfate/phosphate on ferrihydrite: an in situ ATR-FTIR/2D-COS study," Chemical Geology, vol. 477, pp. 12-21, 2018.

[11] C. R. Collins, K. V. Ragnarsdottir, and D. M. Sherman, "Effect of inorganic and organic ligands on the mechanism of cadmium sorption to goethite," Geochimica et Cosmochimica Acta, vol. 63, no. 19-20, pp. 2989-3002, 1999.

[12] J. F. Boily and J. B. Fein, "Experimental study of cadmiumcitrate co-adsorption onto $\alpha-\mathrm{Al}_{2} \mathrm{O}_{3}$," Geochimica et Cosmochimica Acta, vol. 60, no. 16, pp. 2929-2938, 1996.

[13] M. del Nero, C. Galindo, R. Barillon, E. Halter, and B. Madé, "Surface reactivity of $\alpha-\mathrm{Al}_{2} \mathrm{O}_{3}$ and mechanisms of phosphate sorption:_In situ_ATR-FTIR spectroscopy and $\zeta_{-}$potential studies," Journal of Colloid and Interface Science, vol. 342, no. 2, pp. 437-444, 2010.

[14] F. Gerard, "Clay minerals, iron/aluminum oxides, and their contribution to phosphate sorption in soils - a myth revisited," Geoderma, vol. 262, pp. 213-226, 2016.

[15] C. Galindo, M. D. Nero, R. Barillon, E. Halter, and B. Made, "Mechanisms of uranyl and phosphate (co)sorption: complexation and precipitation at $\alpha-\mathrm{Al}_{2} \mathrm{O}_{3}$ surfaces," Journal of Colloid and Interface Science, vol. 347, no. 2, pp. 282-289, 2010. 
[16] E. J. Elzinga and R. Kretzschmar, "In situ ATR-FTIR spectroscopic analysis of the co-adsorption of orthophosphate and Cd(II) onto hematite," Geochimica et Cosmochimica Acta, vol. 117, pp. 53-64, 2013.

[17] C. Tiberg, C. Sjöstedt, I. Persson, and J. P. Gustafsson, "Phosphate effects on copper(II) and lead(II) sorption to ferrihydrite," Geochimica et Cosmochimica Acta, vol. 120, pp. 140-157, 2013.

[18] X. Ren, X. Tan, T. Hayat, A. Alsaedi, and X. Wang, "Cosequestration of $\mathrm{Zn}(\mathrm{II})$ and phosphate by $\gamma-\mathrm{Al}_{2} \mathrm{O}_{3}$ : from macroscopic to microscopic investigation," Journal of Hazardous Materials, vol. 297, pp. 134-145, 2015.

[19] M. A. G. Hinkle, Z. M. Wang, D. E. Giammar, and J. G. Catalano, "Interaction of Fe(II) with phosphate and sulfate on iron oxide surfaces," Geochimica et Cosmochimica Acta, vol. 158, pp. 130-146, 2015.

[20] W. Li, S. Zhang, W. Jiang, and X. Q. Shan, "Effect of phosphate on the adsorption of $\mathrm{Cu}$ and $\mathrm{Cd}$ on natural hematite," Chemosphere, vol. 63, no. 8, pp. 1235-1241, 2006.

[21] A. Singh, K. U. Ulrich, and D. E. Giammar, "Impact of phosphate on U(VI) immobilization in the presence of goethite," Geochimica et Cosmochimica Acta, vol. 74, no. 22, pp. 6324-6343, 2010.

[22] X. Ren, S. Yang, X. Tan, C. Chen, G. Sheng, and X. Wang, "Mutual effects of copper and phosphate on their interaction with $\gamma-\mathrm{Al}_{2} \mathrm{O}_{3}$ : combined batch macroscopic experiments with DFT calculations," Journal of Hazardous Materials, vol. 237, pp. 199-208, 2012.

[23] B. Wan, Y. P. Yan, M. Q. Zhu et al., "Quantitative and spectroscopic investigations of the co-sorption ofmyo-inositol hexakisphosphate and cadmium(II) on to haematite," European Journal of Soil Science, vol. 68, no. 3, pp. 374-383, 2017.

[24] C. Kremer, J. Torres, A. Bianchi, M. Savastano, and C. Bazzicalupi, "Myo-inositol hexakisphosphate: coordinative versatility of a natural product," Coordination Chemistry Reviews, vol. 419, pp. 213-403, 2020.

[25] X. H. Guan, C. Shang, J. Zhu, and G. H. Chen, "ATR-FTIR investigation on the complexation of myo-inositol hexaphosphate with aluminum hydroxide," Journal of Colloid and Interface Science, vol. 293, no. 2, pp. 296-302, 2006.

[26] Y. Yan, W. Li, J. Yang et al., "Mechanism of myo-inositol hexakisphosphate sorption on amorphous aluminum hydroxide: spectroscopic evidence for rapid surface precipitation," Environmental Science \& Technology, vol. 48, no. 12, pp. 67356742, 2014.

[27] Y. P. Yan, F. Liu, W. Li, F. Liu, X. H. Feng, and D. L. Sparks, "Sorption and desorption characteristics of organic phosphates of different structures on aluminium (oxyhydr)oxides," European Journal of Soil Science, vol. 65, no. 2, pp. 308-317, 2014.

[28] B. B. Johnson, E. Quill, and M. J. Angove, "An investigation of the mode of sorption of inositol hexaphosphate to goethite," Journal of Colloid and Interface Science, vol. 367, no. 1, pp. 436-442, 2012.

[29] L. Celi, M. Prati, G. Magnacca, V. Santoro, and M. Martin, "Role of crystalline iron oxides on stabilization of inositol phosphates in soil," Geoderma, vol. 374, p. 114442, 2020.

[30] B. Wan, Y. P. Yan, F. Liu, W. Tan, J. He, and X. Feng, "Surface speciation of _myo_-inositol hexakisphosphate adsorbed on $\mathrm{TiO}_{2}$ nanoparticles and its impact on their colloidal stability in aqueous suspension: A comparative study with orthophosphate," Science of the Total Environment, vol. 544, pp. 134142,2016
[31] X. Feng, Y. Yan, B. Wan et al., "Enhanced dissolution and transformation of $\mathrm{ZnO}$ nanoparticles: the role of inositol hexakisphosphate," Environmental Science \& Technology, vol. 50, no. 11, pp. 5651-5660, 2016.

[32] M. Ruyter-Hooley, A. C. Larsson, B. B. Johnson, O. N. Antzutkin, and M. J. Angove, "The effect of inositol hexaphosphate on cadmium sorption to gibbsite," Journal of Colloid and Interface Science, vol. 474, pp. 159-170, 2016.

[33] M. Ruyter-Hooley, B. B. Johnson, D. W. Morton, and M. J. Angove, "The adsorption of myo-inositol hexaphosphate onto kaolinite and its effect on cadmium retention," Applied Clay Science, vol. 135, pp. 405-413, 2017.

[34] Y. Yan, B. Wan, D. P. Jaisi et al., "Effects of myo-inositol hexakisphosphate on $\mathrm{Zn}$ (II) sorption on $\gamma$-alumina: a mechanistic study," Acs Earth and Space Chemistry, vol. 2, no. 8, pp. 787-796, 2018.

[35] H. du, Q. Huang, R. Yang, B. Tie, and M. Lei, "Cd sequestration by bacteria-aluminum hydroxide composites," Chemosphere, vol. 198, pp. 75-82, 2018.

[36] R. Xu, T. Lyu, M. Zhang, M. Cooper, and G. Pan, "Molecularlevel investigations of effective biogenic phosphorus adsorption by a lanthanum/aluminum-hydroxide composite," Science of the Total Environment, vol. 725, p. 138424, 2020.

[37] K. Eusterhues, F. E. Wagner, W. Häusler et al., "Characterization of ferrihydrite-soil organic matter coprecipitates by X-ray diffraction and Mössbauer spectroscopy," Environmental Science \& Technology, vol. 42, no. 21, pp. 7891-7897, 2008.

[38] W. Li, X. H. Feng, Y. P. Yan, D. L. Sparks, and B. L. Phillips, "Solid-state NMR spectroscopic study of phosphate sorption mechanisms on aluminum (hydr)oxides," Environmental Science \& Technology, vol. 47, no. 15, pp. 130725144353009130725144358315, 2013.

[39] Z. Hu, D. P. Jaisi, Y. P. Yan et al., “Adsorption and precipitation ofmyo-inositol hexakisphosphate onto kaolinite," European Journal of Soil Science, vol. 71, no. 2, pp. 226-235, 2020.

[40] T. Isobe, T. Watanabe, d.' E. de la Caillerie JB, A. P. Legrand, and D. Massiot, "Solid-state $1 \mathrm{H}$ and 27Al NMR studies of amorphous aluminum hydroxides," Journal of Colloid and Interface Science, vol. 261, no. 2, pp. 320-324, 2003.

[41] H. du, Q. Y. Huang, M. Lei, and B. Tie, "Sorption of Pb(II) by nanosized ferrihydrite organo-mineral composites formed by adsorption versus coprecipitation," Acs Earth and Space Chemistry, vol. 2, no. 6, pp. 556-564, 2018.

[42] Q. Xue, Y. Ran, Y. Z. Tan, C. L. Peacock, and H. du, “Arsenite and arsenate binding to ferrihydrite organo-mineral coprecipitate: implications for arsenic mobility and fate in natural environments," Chemosphere, vol. 224, pp. 103-110, 2019.

[43] Q. Sun, C. Liu, P. Cui et al., "Formation of Cd precipitates on $\gamma$ $\mathrm{Al}_{2} \mathrm{O}_{3}$ : implications for $\mathrm{Cd}$ sequestration in the environment," Environment International, vol. 126, pp. 234-241, 2019.

[44] H. du, Z. L. Xu, M. Hu et al., "Natural organic matter decreases uptake of $\mathrm{W}(\mathrm{VI})$, and reduces $\mathrm{W}(\mathrm{VI})$ to $\mathrm{W}(\mathrm{V})$, during adsorption to ferrihydrite," Chemical Geology, vol. 540, article 119567, 2020.

[45] Z. He, C. W. Honeycutt, T. Zhang, and P. M. Bertsch, "Preparation and FT-IR characterization of metal phytate compounds," Journal of Environmental Quality, vol. 35, no. 4, pp. 1319-1328, 2006.

[46] T. Cai, X. L. Liu, J. C. Zhang et al., "Silicate-modified oiltea camellia shell-derived biochar: A novel and cost- effective sorbent for cadmium removal," Journal of Cleaner Production, vol. 281, p. 125390, 2021. 